\title{
Subjective Distresses of Nasogastric Tube Feeding
}

\author{
Geraldine V. Padilla, Ph.D., Marcia Grant, R.N., M.S.N., Hilda Wong, R.N., M.A.N., Barbara W. \\ Hansen, Ph.D., Robert L. Hanson, R.N., M.N., Nancy Bergstrom, R.N., M.S., \\ and Winifred R. Kubo, R.N., M.S.
}

City of Hope National Medical Center, Duarnte, California, California State College, Sonoma, California, University of Michigan, East Lansing, Michigan, and University of Hawaii, Honolulu, Hawaii

\begin{abstract}
Health care professionals assume that tube feeding is an unpleasant, distressing experience for patients, which is only partially substantiated by experience. Thirty patients were interviewed via a tube feeding and hospital experience checklist (a 47-item interview schedule). Common experiences were operationally defined as those felt by at least $50 \%$; subjectively distressful experiences were those identified by patients as causing distress. The most common and most distressful experiences of nasogastric tube feeding were: sensory irritations and sensory deprivation. The psychosensory irritation experiences were: thirst, sore nose or throat, dry mouth, runny nose, a tube in the nose, taking food through a tube, breathing
\end{abstract}

through the mouth, breathing with a tube in the nose, taking food in a treatment type container, and taking food with a different texture and smell than usual. The psychosensory deprivation experiences were: an unsatisfied appetite for certain foods, deprivation of tasting, chewing, swallowing food, and drinking liquids, limited mobility, and deprivation of regular food. Except for burping, gastrointestinal symptoms were not common though they were usually distressful. This information has been used to develop teaching programs which are being tested for effectiveness in reducing distress associated with nasogastric tube feeding.
Nasogastric tube feeding reduces the process of eating to its barest essential, that of providing nourishment to the patient. By its very nature, tube feeding drastically limits the sensory pleasures which normally accompany eating. The procedure, together with the attitude among health professionals that emphasizes appropriate. nourishment as part of treatment and feeding as a food delivery task, contributes toward the desocialization of the eating process. ${ }^{1}$ Tube feeding is further related to the unpleasant and often painful experience of disease, hospitalization, and surgery. For these reasons, health care professionals regard tube feeding as a frequently necessary though unpleasant procedure for patients; yet, very little research has been done to find effective ways of improving the tube feeding experience.

A review of the literature suggests that there are different classes of distressful experiences associated with tube feeding: (1) psychosocial, in that it limits the cultural, social, and religious components of eating ${ }^{2,3}$ and is usually experienced concurrently with pain and nervousness, ${ }^{4}$ a tube-fed patient may be nutritionally sated but still remain "hungry" and "unsatisfied;", 2,5 ) those related directly to the tube feeding formula; ${ }^{5,6}$ if the smell and taste of the feeding is associated with unpleasant gastrointestinal responses such as nausea, vomiting, abdominal cramps, regurgitation, heartburn, bloatedness, etc., then the feeding itself-its appearance, smell, texture, consistency, taste-might induce distress; ${ }^{6} 3$ ) the physical discomforts related to $i t^{7-16} 4$ ) the physical discomforts associated with the limitation of normal eat. ing sensations; ${ }^{17-22} 5$ ) physical gastrointestinal distresses, such as eructation, nausea, vomiting, regurgitation, flatulence, borborygmi, abdominal cramps, abdominal distention, diarrhea, and constipation. . $3-41^{2}$

These unpleasant and distressing aspects strongly sug- gest that tube feeding is a negative experience. However, much of the information in this area has been based on research with animals, medical records of discharged patients, and on unvalidated observations; very few are based on clinical studies of patients. The following report is a sample of alert tube-fed patients studied in order to determine the type, incidence, and subjective level of distress experiences associated with tube feeding.

\section{METHODS}

\section{Subjects}

Data were analyzed from 30 subjects ( 28 hospital patients and 2 University students); 23 were from Los Angeles County, 3 from Honolulu, and 4 from Seattle. Of the original 38 subjects interviewed, 8 were dropped from the final analysis. Of these 8 individuals, 4 were used for identifying possible interview problems such as misunderstood questions or frequency of interruptions, 2 did not want to complete the interview, and 2 were confused at the time of the interview.

The typical subject was from a county or private hospital, male, over 40 years of age, caucasian, of average height and build, had lost weight in the last 6 months, and was ambulatory. Most subjects ( $80 \%$ or more) reported no milk, fat, or food intolerance; 8 reported medication or drug allergies; 15 were current smokers. Most subjects required no special medications, treatments or diets, had health problems under control with medications and treatments, and good cardiovascular and renal status. The sample omits a large number of tube feeding patients with central nervous system deficits, since most of them are not usually alert enough to participate in an interview. Most subjects had normal respiratory readings, no fever, normal systolic and diastolic blood pres- 
sure and pulse readings. Almost all reported 7 or more normal or soft-formed stools per week, and most had never taken a laxative or enema. At the time of study, 28 had been on tube feeding for no less than 2 days and no more than 2 weeks; 2 had been on tube feeding for more than 2 weeks. Most were undergoing tube feeding as a consequence of cancer, trauma to skin or membrane, or other problems of the ear, nose, throat, and neck area. Nasogastric tubes were made of either rubber or plastic, and were size $\# 12-, 14-$, or 16 -French. Tube feedings were usually administered by gravity, with a frequency of 4 to 6 feedings/day given at room temperature, with the subjects either in a semi or high Fowler position. In a 24hour period, the range of liquid diet through the nasogastric tube was 300 to $1800 \mathrm{ml}$, with an additional 150 to $2700 \mathrm{ml}$ water. Patients did not usually have other oral intake, though they were likely to have some intravenous fluids. The variability in tube feeding administration identified in this study reflects typical practice. ${ }^{4}$

\section{Data Collection}

The study consisted of interviews with persons undergoing tube feeding who consented to answer questions about this experience, and was conducted in accord with the principles for human experimentation summarized in the Declaration of Helsinki.

A Study Period Constants tool was used to collect demographic and history data. A 24-hour Data Collection Form was used to collect information on vital signs, characteristics of the tube used for feeding, and the procedure, content, intake and output, as well as medications and treatments. The form was developed and tested through the Walike et al study, ${ }^{4}$ modified for the present study.

The Tube Feeding and Hospital Experiences Checklist (TFHECL) is a tool developed by the investigators and used to identify the subjective level of patient distress associated with tube feeding and other hospital experiences.

The different hospital experiences were selected as reflecting various known levels of distress ${ }^{42,43}$ for nontube feeding hospital experiences and serve as points of comparison for tube feeding-related experiences. Patients identified the relevance of each checklist item to their own experience and indicated verbally or nonverbally whether they had this experience (coded as 1), or not (coded as 2) and the level of distress they associated with the distress (coded 3 to 6 ). The number codes 1 and 2 identify a simple two-choice alternative of presence or absence of the experience; codes 3 to 6 represent a rank scale of levels from none $(=3)$ to extreme distress $(=6) .^{44}$ The viability of the scale was tested with 10 patients who reported no difficulty in filling out the checklist. Completion time for the TFHECL for 24 subjects was 19 minutes, with a 10 to 52-minute range.

The tool included experiences related to the social aspects of tube feeding, hunger, the feeding diet itself, the tube, physical experiences involving the throat, mouth, and nares; deprivations imposed by the tube feeding; gastrointestinal symtoms; and general hospital experiences, such as pain from surgery or wearing an identification band.
Information pertaining to the affective state of the subjects at the time of the interview was gathered with the Mood Adjective Checklist (MACL) of Myers. ${ }^{45}$ Radloff and Helmreich ${ }^{46}$ reported this to be the most reliable and valid index of individual response to stressful situa. tions. The present investigators have used the Johnson ${ }^{47}$ version of the MACL, adding a sixth set of adjectives to evaluate anxiety (anxious, troubled, disturbed, worried, tense). This form of the MACL usually took 7 minutes to complete, but as short a time as 3 and as long as 11 minutes. Patients were asked to indicate how they were feeling at the moment with respect to each mood adjective. As with the TFHECL, the resulting codes represented a rank scale of levels of mood from not experiencing the mood $(=1)$ to feeling the mood very much $(=4)$.

A standardized data collection procedure was used to resolve problems usually encountered with multiple data collectors in multiple clinical settings. The preferred interview approach as well as typical problems were videotaped. Such problems as interruption, difficulty in understanding the question, tiring during the interview, leading the interviewer away from the focal areas into other conversation areas, and the solutions role-played on the videoscreen, then shown to the data collectors from the different study sites at a training session. Interrater reliability was determined on 5 subjects (there was agreement on $95 \%$ of the information).

The data collectors surveyed the participating hospitals daily to ascertain whether any patients were starting tube feeding. Potential subjects were informed of the purpose of the study and asked to participate! Those who consented were then interviewed after the third postoperative day. Medical records were used to collect other data. A frequency count was computed of the values in each variable in the 24-hour Data Form.

\section{RESULTS AND DISCUSSION}

When principal factor analysis with iteration, followed by varimax rotations, was computed on the MACL data to determine its construct validity for this sample, 6 factors were extracted. The variables that loaded most highly on each of these factors were: Factor 1: helpless .83; dependent .75; disturbed .74; Factor 2: annoyed .77; angry .77; hostile .69; Factor 3 : indignant .72; downcast .65 ; blue .65; Factor 4: vigorous .75; alert .59; energetic .55 ; Factor 5: jittery .81; gloomy .52; tense .51; Factor 6: afraid .64; scared stiff .60; depressed .52. These reflected the affective states of helplessness (Factor 1), anger (Factor 2), blueness (Factor 3), alertness (Factor 4), jitteryness (Factor 5), and fear (Factor 6). These data confirm that the MACL did have construct validity for our population of patients. For the most part, the adjectives measured the different types of affect states they were designed to measure.

The responses of the subjects to the MACL indicated that most felt helpless (17), dependent (20), not annoyed 18), not angry (24), not afraid (18), and not scared stiff (19). Most did not feel or were just a little downcast (22), blue (21), jittery (23), tense (20). Approximately half did not feel vigorous (16), or energetic (15). The data indicate that subjects are 'typical' in that they fit the sick role dependency attitude. The data also suggest that their 
responses can be taken to reflect tube feeding experiences and not a generalized negative affect state.

Analyses of the TFHECL focused on the type, incidence, and level of distress of experiences. In order to identify the different types of tube feeding experiences, a cluster analysis was computed on common ( $\geq 50 \%$ of subjects) tube feeding experiences for which the level of distress was $\geq 3.1$ (Table I). The measure of similarity used in this analysis was the absolute value of the correlation. The rule used (to combine variables into clusters or clusters into larger clusters) was that of maximum similarity (single linkage). Two distinct clusters were identified, one of which included 3 subclusters. The first identified psychosocial type tube feeding distresses: "being deprived of socializing while eating" and "hearing sounds from the stomach" (which may have been related to social embarrassment). On a scale of 0 to 100 the similarity value of the experiences in this cluster is low (34.93).

The second cluster can be labeled the psychosensory type and includes 16 variables with a low similarity value of 39.72 . Within this cluster are 3 stronger clusters which further classify different types of psychosensory experiences. The first subcluster is composed of distressful experiences brought on by oro-nasal-pharyngeal sensory responses to tube feeding. Specifically, the analysis showed that "feeling thirsty" was the most distressing of the common tube feeding experiences clustered together with other sources such as taking food through a tube instead of through the mouth, taking food with a different smell, and breathing through the mouth. The similarity value for this cluster of four variables is 41.30 . The second subcluster includes sensory experiences which are gastrointestinal and include "burping" and "having an unsatisfied appetite for certain foods," with a similarity value of 53.34. The third subcluster is characterized by distresses in response to sensory deprivation, such as "being deprived of tasting food," the second most distressing common experience, clustered together with four other food stimulus deprivation experiences, with a sim. ilarity value of 56.95. The other experiences in the cluster are "being deprived of chewing, drinking, and swallowing food." Thus, 2 of the 3 psychosensory subclusters emphasize the importance of oro-nasal-pharyngeal sensations as sources of discomfort in tube feeding and specifically point out that the absence of normal amounts of water-and-food-related stimuli cause the most common tube feeding discomforts.

The cluster analysis indicated that the tube feeding experiences in the TFHECL tool form some gross clusters which characterize types of experience. However, some important ones, such as "having a sore nose or throat,"

TABLE I

A rank order of mean distress scores for most common ( $N$ is $\geq 50 \%$ of subjects) experiences on TFHECL

\begin{tabular}{|c|c|c|c|}
\hline List of Common Experiences & $\begin{array}{l}\text { Incidence } \\
\mathrm{N}\end{array}$ & $\begin{array}{l}\text { Percent of Total } \\
\quad N(30)\end{array}$ & $\begin{array}{l}\text { Level of Distress } \\
\text { Mean Score }\end{array}$ \\
\hline Having pain from the surgery or disease $\left(\mathrm{H}^{b}\right)$ & 21 & 70 & 5.048 \\
\hline Feeling thirsty (T) & 16 & 53 & 4.813 \\
\hline Being away from home and family $(\mathrm{H})$ & 27 & 90 & 4.778 \\
\hline Being deprived of tasting food (T) & 27 & 90 & 4.741 \\
\hline $\begin{array}{l}\text { Being concerned about outcome of surgery or disease or procedure } \\
\text { (H) }\end{array}$ & 22 & 73 & 4.682 \\
\hline Losing control of daily activities $(\mathrm{H})$ & 25 & 83 & 4.680 \\
\hline Having unsatisfied appetite for certain foods (T) & 25 & 83 & 4.640 \\
\hline Sore nose or throat $(\mathrm{T})$ & 25 & 83 & 4.640 \\
\hline Dry mouth $(\mathrm{T})$ & 16 & 53 & 4.500 \\
\hline Being deprived of drinking liquids $(T)$ & 26 & 87 & 4.385 \\
\hline Being deprived of chewing food (T) & 26 & 87 & 4.231 \\
\hline Having a runny nose $(\mathrm{T})$ & 23 & 77 & 4.217 \\
\hline Having a tube in my nose (T) & 30 & 100 & 4.133 \\
\hline Having limited mobility because of the tube (T) & 15 & 50 & 4.067 \\
\hline Taking food through a tube instead of through the mouth (T) & 28 & 93 & 4.000 \\
\hline Being deprived of swallowing food (T) & 26 & 87 & 4.000 \\
\hline Having blood drawn (H) & 24 & 80 & 3.958 \\
\hline Breathing through the mouth (T) & 15 & 50 & 3.733 \\
\hline Hearing sounds from the stomach $(\mathrm{T})$ & 17 & 57 & 3.647 \\
\hline Breathing with a tube in the nose (T) & 28 & 93 & 3.643 \\
\hline $\begin{array}{l}\text { Being deprived of food eaten by other patients while being exposed to } \\
\text { these foods (T) }\end{array}$ & 25 & 83 & 3.560 \\
\hline Having others see me with tube in my nose (T) & 29 & 97 & 3.379 \\
\hline Having to share a bathroom with a stranger $(H)$ & 16 & 53 & 3.375 \\
\hline Being scrutinized by doctors, nurses, etc. (H) & 25 & 83 & 3.360 \\
\hline Having to take food under hospital conditions (H) & 28 & 93 & 3.357 \\
\hline Burping $(\mathrm{T})$ & 16 & 53 & 3.250 \\
\hline Being deprived of socializing while eating $(\mathrm{T})$ & 17 & 57 & 3.235 \\
\hline Taking food from a medical treatment type container $(\mathrm{T})$ & 28 & 93 & 3.214 \\
\hline Taking food by tube with a different texture than usual (T) & 29 & 97 & 3.172 \\
\hline Taking food by tube with a different smell than usual (T) & 24 & 80 & 3.125 \\
\hline Taking food by tube with a different appearance than usual (T) & 29 & 97 & 3.069 \\
\hline Taking food by tube with a different consistency than usual (T) & 25 & 83 & 3.040 \\
\hline Having to wear an identification wristband $(\mathrm{H})$ & 26 & 87 & 3.000 \\
\hline
\end{tabular}

" Score values ranged from 3 (least distressing) to 6 (most distressing).

${ }^{b} \mathrm{H}$, general-type hospital experience; $\mathrm{T}$, specific tube-feeding experience. 
did not form a meaningful cluster together with other variables such as "runny nose" or "breathing with a tube in my nose." Further research is needed on this.

Table I summarizes the data gathered for the 30 tubefed subjects when a frequency count was computed for the values of each item in the TFHECL and rank orders the mean distress scores for the most common experiences associated with tube feeding or hospitalization. The most distressing experience commonly felt was "pain from surgery or disease" while the least distressing experience was "wearing an identification band." The other common hospital experiences also serve as points of comparison for tube feeding experiences.

The most common and distressing experiences associated with tube feeding were 1) "feeling thirsty," a discomfort in the mouth and throat area which is an important indicator of hydration status; 2) "being deprived of tasting food," taste being one of the primary psychosensory stimuli for eating; 3) "having an unsatisfied appetite for certain foods," which is closely related to the second and as important as "being away from home and family," "being concerned about the outcome of surgery, disease, or procedure," and "losing control of daily activities." Thus, psychosensory distress is important when evaluating tube feeding experience.

The fourth common distressing experience was physical: "sore nose or throat." However, because a large number of subjects with cancer or surgery of the ear, nose, throat, and neck or trauma to skin or membrane in the face and throat area reported soreness, it is difficult to determine whether that is a consequence of the tube, the diagnosis, or the surgery. Other psychosensory discomforts were "being deprived of drinking liquids (or chewing foods);" "having limited mobility becàuse of the tube;" "being deprived of swallowing food;" "hearing sounds from the stomach;" and "being exposed to the sights and sounds of regular food eaten by other patients while being deprived of these foods." Additional common discomforts related to tube feeding were "dry mouth;" "having a runny nose;" "breathing through the mouth;" and "breathing with a tube in the nose."

By chi square computation for number of days on tube feeding (first $48 \mathrm{hrs}, 3$ to 5 days, $6+$ days), level of distress (none, a little, somewhat, very), "having a tube in my nose" and of "taking food through a tube instead of through the mouth" showed no significant difference in distribution of subjects. These data suggest that the common distresses are not limited to new tube feeding patients nor do they become habituated to these discomforts.

Analysis of Variance computed for the presence or absence of a tracheostomy and the level of distress associated with "dry mouth," "sore nose or throat," "breathing through the mouth," "swallowing more than usual," and "feeling thirsty." showed no significant differences. This suggests that the presence or absence of a tracheostomy does not significantly increase or decrease the distress associated with tube feedings.

Because of their implications for patient care, other experiences which cause distress despite their lack of frequency include a number of gastrointestinal responses: "having abdominal cramps," "regurgitation," "feeling heartburn, bloated, constipated, hungry, and gas," "having diarrhea," "nausea," and "vomiting". Physical discomforts located in the head and neck region included "burning across the upper facial area," "having a bad taste in the mouth," "feeling something (water) in the ear," "swallowing more than usual," and "pulling of tape on the face." Two others are related to the disruption of normal stimuli for food intake: "not knowing when I've had enough food," and "having a poor appetite." Knowledge of these experiences is valuable for those who care for tube-fed patients.

After the distresses were identified, 18 nurses and 2 doctors familiar with the problems of tube-fed patients were asked to identify clinical interventions to reduce the psychosensory and psychosocial distresses of tube feeding. Their general recommendations are that, since tube feeding is different from normal eating, a certain amount of adjustment is necessary. Patients should be encouraged to ask questions and discuss their experiences and to report discomforts or changes in levels of discomfort. Specific recommendations for psychosensory distress are:

1. If the patient has a dry mouth and breathes through the mouth, urge breathing through the nose as much as possible. For dry mouth and lips, the patient can rinse often with water or mouth wash and moisten or lubricate the lips, brush the teeth, suck lemon drops, or chew gum if permitted. For feelings of thirst, additional water should be urged. For a sore throat and frequent swallowing, the patient can rinse and gargle with warm water and salt, or with mouth wash. For a sore nose, the patient should blow gently and clean and lubricate regularly with water or glycerine. If the tube is uncomfortable, it may be pulled out gently, cleaned with a moistened gauze or cotton applicator, then reinserted to its original position, although it may be necessary to reinsert the tube in the other nostril or to retape it.

2. Tell the patient it is important to sit during and after feeding to prevent the feeding from backing up. The patient may feel discomfort as the formula enters the stomach, but the feeding should go more easily if the patient relaxes. Urge deep breathing, as this increases relaxation. It may help to interrupt the feeding momentarily, and can be continued when the patient feels better. When there is an unsatisfied appetite for certain foods, a favorite food can be blenderized and included in the diet.

3. When patients experience sensory eating and drinking deprivations, instruct them to state their meal preferences: for example having the feeding warm or cold, in small or large portions, or served in a teapot. It may be distressing to see and smell the food eaten by other patients while being deprived of these foods, so some may prefer to have their doors closed or curtains drawn. Also, the formula could be flavored to enhance the smell. Since food usually cannot be tasted via the tube, patients may feel unsatisfied and may find it distressing to be deprived of chewing and swallowing food. If permitted, a favorite food can be chewed and spit out, or gum can be chewed. Patients who feel deprived of drinking liquids should be instructed to rinse the mouth frequently and, if permitted, to request additional water. If there is less 
mobility because of the tube, inform the patient that, as he or she gets used to the tube, it will be more comfortible doing things. Also instruct them to change position in bed from time to time, or to walk around the hospital unit. These activities will help the patient feel less con-tricted.

4. The patient who feels deprived of socializing while tating may prefer to have the tube feeding at the same time as others have their meals. Conversely, patients who are distressed from the tube in the nose, or by loud stomach sounds may prefer privacy during tube feeding. Eor those who are generally distressed by their appearince with a tube in the nose, there is little comfort except :o conceal part of the tube under clothing.

We have used this information to develop teaching programs which are presently being tested for effectiveness in reducing distress associated with nasogastric tube feeding.

\section{ACKNOWLEDGEMENT:}

This study was supported by PHS-NU 00523, City of Hope, University of Washington, and University of Hawaii.

\section{REFERENCES}

1. Habeeb MC: Eating, Illness, and Identity: A Study of the Relationship of the Meaning of Eating and Illness Experience of Hospital. ized Adults. Unpublished doctoral dissertation, University of California, San Francisco, 1973.

2. Bruch H: Eating Disorders. New York, Basic Books, 1973.

3. Fleshman RP: Eating rituals and realities. Nurs Clin North Am 8: 1:91-104, 1973.

4. Walike BC, Padilla GV, Bergstrom $N$ et al: Patient problems related to tube feeding. Communicating Nursing Research 7:89-112. Boulder, Colorado, Western Interstate Commission for Higher Education, 1975.

5. Mason JW: A re-evaluation of the concept of non-specificity in stress theory. J Psychiatry 8:323-333, 1971.

6. Garcia J, Koelling RA: Relation of cue of consequence in avoidance learning. In Seligman MEP, Hager JL (eds): Biological Boundaries of Learning. New York, Appleton-Century-Croft, pp. 10-14, 1972.

7. Kehue M: Pain and gastric acid secretion. J Psychosom Res 15:47$53,1971$.

8. Heitkemper M, Hanson R, Hansen BC: The Effects of Rate and Volume of Tube Feeding in Normal Human Subjects. Paper presented at Tenth Annual Communicating Nursing Research Conference, Denver, Colorado, May, 1977.

9. Brand JB, Emerson CW, Wilson RS: Acute laryngeal edema 24 hours after passage of a nasogastric tube. Anesthesiology 45:555557,1976 .

10. DeWalt EM, Haines AK: Effects of specified stressors on healthy oral mucosa. Nurs Res 18:22-27, 1969.

1. Barron J. Tube feeding of postoperative patients. Surg Clin North Am 39:1481-1491, 1959.

2. Brunner LS et al: Textbook of Medical-Surgical Nursing. New York, Lippincott Co, 1970.

3. Fuerst EV, Wolff L: Fundamentals of Nursing. Philadelphia, JB Lippincott Co, 1969.

4. Marlow DR, Sellew G: Textbook of Pediatric Nursing. Philadelphia, WB Saunders, 1967.
15. Noyes A, Haydon EM, vanSickel M: Textbook of Psychiatric Nursing, 5th dd. New York, MacMillan Co, 1957.

16. Shafer KN' et al:-Medical Surgical Nursing. St. Louis, CV Mosby Co, 1967.

17. Beland IL: Clinical Nursing Pathophysiological and Psychosocial Approaches, 2nd ed. New York, MacMillian, 1970.

18. Gorman W: Flavor, Taste and the Psychology of Smell. Springfield, Illinois, Charles C Thomas, 1964.

19. Smith AV: Nasogastric tube feeding. Am J Nurs 57:1451-1452, 1957.

20. Epstein AN: Psychological aspects of food intake. In Regulation of Hunger and Satiety. Proceedings of the Seventh International Congress of Nutrition, Hamburg, Germany, 1966.

21. Galperin SI, Rubinov IG: The effect of unconditioned and conditioned stimuli on periodic motor activity of the stomach and duodenum in dogs. Acta:Biologiae Experimentalis 28:98-106, 1968.

22. Jordan HA: Voluntary intragastric feeding: oral and gastric contributions to food intake and hunger in man. J Comp Physiol Psychol 68:498-506, 1969.

23. Day S, Buckell M: Feeding the Unconscious Patient. Proceedings of the Nutrition Society 30:184-190, 1971.

24. DuGas BW: Kozier-DuGas' Introduction to Patient Care: A Comprehensive Approach to Nursing, 2nd ed. Philadelphia, WB Saunders Co, 1972.

25. Fallis LS, Barron J: Gastric and jejunal alimentation with fine polyethylene tube. Arch Surg 65:373, 1952.

26. Gormican A: Prepackaged tube feedings. Hospitals 44:58-60, 1970.

27. Kee J: Fluid imbalance in elderly patients. Nursing '73 3:40-43, 1973.

28. Krause M: Food, Nutrition, and Diet Therapy, 4th ed. Philadelphia, WB Saunders Co, 1966.

29. Metheny NM, Snively WD: Nurses Handbook of Fluid Balance. Philadelphia, JB Lippincott Co, 1967.

30. Mitchell HS et al: Cooper's Nutrition in Health and Disease, 15th ed. Philadelphia, JB Lippincott, 1968.

31. Williams SR: Nutrition and Diet Therapy, 2nd ed. St. Louis, CV Mosby Co, 1973.

32. Wohl MG, Goodhard $\mathrm{R}$ (eds): Modern Nutrition in Health and Disease, 3rd ed. Philadelphia, Lea \& Febiger, 1964.

33. Cuatrecasas P, Lockwood DH, Caldwell JR: Lactose efficiency in the adult. Lancet 1:14-18, 1965.

34. Gormican L, Liddy E: Nasogastric tube feedings. Postgrad Med 53: 71-76, 1973.

35. Huang SS, Baylass TN: Lactose intolerance in healthy children. $\mathrm{N}$ Engl J Med 276:1283-1287, 1967.

36. Jones ES, Peaston MJT: Metabolic care during acute illnesses. Practitioner 196:271-275, 1966.

37. Krehal WA: Tube feeding. J Am Med Assoc 169:1153, 1959.

38. Metzmeier C, McDowell F: New formulas for tube feeding. NY State J Med 61:2061-2064, 1961.

39. Noone RB, Graham WP: Nutritional care after head and neck surgery. Postgrad Med 53:7:80-86, 1973.

40. Pareira MD et al: Therapeutic nutrition with tube feeding. J Am Med Assoc 156:810-816, 1954.

41. Walike BC, Walike JS: Lactose content of tube feeding diets as a cause of diarrhea. The Laryngoscope 83:1109-1115, 1973.

42. Volicer BJ: Perceived stress levels of events associated with the experience of hospitalization: development and testing of a measurement tool. Nurs Res 22:6:491-497, 1973.

43. Volicer BJ: Patients' perceptions of stressful events associated with hospitalization. Nurs Res 23:3:235-238, 1974.

44. Shaw ME, Wright JM: Scales for the Measurement of Attitudes. New York, McGraw-Hill Book Co, 1967.

45. Myers T: Mood Adjective Checklist. Unpublished research, Naval Medical Research Institute, Bethesda, Maryland, 1966.

46. Radloff R, Helmreich R: Groups Under Stress: Psychological Research in Sealab II. New York, Appleton-Century-Croft, 1968.

47. Johnson JE: Effects of accurate expectations about sensations on the sensory and distress components of pain. J Pers Soc Psychol $27: 261-275,1973$. 